\title{
Perfil sociodemográfico e história penal da população enCARCERAda de uMa penitenciária feminina do interior do estado de São Paulo
}

\author{
Zeyne Alves Pires Scherer' ${ }^{1}$ Edson Arthur Scherer'; \\ Andressa Duarte Nascimento ${ }^{3}$; Fábio Dias Ragozo ${ }^{4}$
}

\begin{abstract}
Neste estudo o objetivo foi traçar o perfil sociodemográfico e a história penal das mulheres encarceradas da Penitenciária Feminina de Ribeirão Preto, utilizando o prontuário processual e de saúde. A população foi de 310 mulheres, na maioria jovens, brancas, naturais do Estado de São Paulo, solteiras, com pelo menos um filho, católicas, baixa escolaridade e ocupações relacionadas. Envolvimento com drogas (tráfico e uso) foi o delito mais observado. A maioria cumpria pena de 1 a 12 anos e estava aprisionada pela primeira vez. Percebeu-se que os prontuários estavam com dados incompletos. Os profissionais precisam reconhecer a importância dos registros e ser incentivados a fazê-los.
\end{abstract}

Descritores: Mulheres; Prisões; Violência; Fatores Socioeconômicos.

\footnotetext{
${ }^{1}$ Enfermeira, Doutor em Enfermagem, Professor Doutor, Escola de Enfermagem de Ribeirão Preto, Universidade de São Paulo, Centro Colaborador da OMS para o Desenvolvimento da Pesquisa em Enfermagem, SP, Brasil. E-mail: scherer@eerp.usp.br.

2 Psiquiatra, Doutor em Patologia Experimental, Hospital das Clínicas, Faculdade de Medicina de Ribeirão Preto, Universidade de São Paulo, $\mathrm{SP}$, Brasil.

${ }^{3}$ Aluna do curso de Graduação em Enfermagem, Escola de Enfermagem de Ribeirão Preto, Universidade de São Paulo, Centro Colaborador da OMS para o Desenvolvimento da Pesquisa em Enfermagem, SP, Brasil. Bolsista de Iniciação Científica (PIBIC) do Conselho Nacional de Desenvolvimento Científico e Tecnológico (CNPq).

${ }^{4}$ Aluno do curso de Graduação em Direito, Faculdades COC, Ribeirão Preto, SP, Brasil.
}

\section{Endereço para Correspondência}




\section{SOCIODEMOGRAPHIC PROFILE AND PENAL HISTORY OF THE PRISON POPULATION}

\section{at a female Penitentiary in the interior of São Paulo state}

We aimed to draw a sociodemographic profile and penal history of women imprisoned at the Ribeirão Preto Female Penitentiary, using their trial and health records. The population consisted of 310 women, mostly young, white, from São Paulo State, single, with at least one child, catholic, low education level and related occupations. As to their penal history, involvement with drugs (traffic and consumption) was the most frequent crime. Most fulfilled penalties of 1 to 12 years and were imprisoned for the first time. We noticed that the records were incomplete. Professionals need to recognize the importance of the registers and be encouraged to make them.

Descriptors: Women; Prisons; Violence; Socioeconomic Factors.

\section{Perfil sociodemográfico e historia penal de la población Carcelaria de una Penitenciaría femenina del estado de São Paulo}

La finalidad del estudio fue trazar un perfil sociodemográfico e historia penal de las mujeres encarceladas de la Penitenciaría Femenina de Ribeirão Preto, utilizando su archivo procesal y de salud. La población fue de 310 mujeres, la mayoría jóvenes, blancas, naturales del estado de São Paulo, solteras, con al menos un hijo, católicas, baja escolaridad y ocupaciones relacionadas. Respecto a la historia penal, el involucramiento con drogas (tráfico y uso) fue el delito más observado. La mayoría cumplía pena de 1 a 12 años y estaba aprisionada por la primera vez. Percibimos los registros con datos incompletos. Los profesionales precisan reconocer la importancia de los registros y ser incentivados a hacer-los.

Descriptores: Mujeres; Prisiones; Violencia; Factores Socioeconómicos.

\section{Introdução}

Ao longo de sua evolução, a raça humana tem investido em formas de contenção e punição da violência e suas mais diversas manifestações, no intuito de proteger seus cidadãos dos indivíduos que têm atitudes violentas. A expectativa é de que os castigos sirvam para coibir a recorrência dessas atitudes, e de que outras pessoas cometam atos semelhantes. As penalidades vão desde advertências verbais e por escrito, passando por punições de ordem monetária (multas) previstas em códigos de condutas, até chegar à necessidade de instalar processos judiciais que podem culminar em penas variadas ${ }^{(1)}$. Nessas, estão incluídas a imposição de limites (ou restrição) de contato dos perpetradores com as vítimas; prestação de serviços gratuitos à comunidade, pagamento de benefícios ou indenizações e diferentes períodos de reclusão em diversos regimes de privação de liberdade a serem cumpridas, em instituições prisionais (colônias penais, penitenciárias, manicômios judiciários e outros $)^{(1)}$.

É possível observar, ao longo da história, que a existência das prisões é anterior à edição das leis penais. Surgiu com o objetivo de controlar os indivíduos e punilos com a ausência total de liberdade e repressão de seus instintos violentos. $\mathrm{O}$ cárcere tem, em sua essência, o caráter transformador dos indivíduos, recorrendo, para isso, ao isolamento social, ao trabalho (por vezes imposto em algumas instituições) e às técnicas corretivas ${ }^{(2)}$. $\mathrm{Na}$ atualidade, é sabido, porém, que tais medidas são ineficazes, quando é discutida a reinserção desses indivíduos na sociedade, o que os leva à reincidência no crime e consequente retorno à prisão $\mathrm{O}^{(3)}$. 
Ao se deparar com uma população carcerária feminina, a problemática da violência pode tomar dimensões diversas. Além de perpetradoras de algum tipo de violência, essas mulheres podem ser, também, vítimas, ao longo de suas vidas e mesmo durante seu período de encarceramento. Estudos brasileiros têm demonstrado que essa população tende a ser jovem, de baixo nível socioeconômico e educacional, com história de prostituição e uso abusivo de álcool e drogas ilícitas e, na maioria dos casos, condenada por envolvimento com o tráfico de drogas ${ }^{(3-5)}$.

Frente aos resultados de pesquisas referentes à população de mulheres que se encontram cumprindo penas em presídios no Brasil,,fica evidente a importância de se conhecer o perfil e a história penal das mesmas. Em momentos diferentes, pode haver mudanças nas características das pessoas que se encontram aprisionadas. No entanto, as informações disponibilizadas por um perfil como esse podem servir como fonte para comparações entre populações de diferentes instituições prisionais, tanto para pesquisadores quanto para os profissionais, governantes e demais responsáveis envolvidos na manutenção dessas estruturas. Como consequência, essas informações podem ter utilidade em discussões acerca do planejamento e aprimoramento das condições envolvidas no processo de encarceramento de mulheres, em especial, no que se refere à saúde destss, com base na recente publicação, pelo Ministério da Saúde, de política pública voltada para esse grupo. Portanto, por essas considerações, houve a motivação para se conhecer o perfil sociodemográfico e a história penal de mulheres aprisionadas em uma penitenciária feminina do interior do Estado de São Paulo.

\section{Método}

Este estudo configura-se como pesquisa documental indireta $^{(6)}$, na qual foram utilizadas fontes primárias (pesquisa documental) e fontes secundárias (pesquisa bibliográfica). Foi realizado na Penitenciária Feminina de Ribeirão Preto, onde as detentas (nessa instituição denominadas reeducandas) cumprem penas privativas de liberdade, em regime fechado. Essa instituição tem capacidade para abrigar 300 reeducandas.

Os sujeitos deste estudo foram 310 reeducandas, o que abrangeu a totalidade da população carcerária da instituição, no período da coleta de dados, de setembro a novembro de 2006.

$\mathrm{O}$ projeto de pesquisa foi autorizado pelo diretor da Penitenciária Feminina de Ribeirão Preto e aprovado (Protocolo $\left.\mathrm{n}^{\circ} 0673 / 2006\right)$ pelo Comitê de Ética em Pesquisa da Escola de Enfermagem de Ribeirão Preto, da Universidade de São Paulo.

A coleta de dados foi realizada mediante o preenchimento de um protocolo de pesquisa criado pelos autores, contemplando informações referentes a aspectos sociodemográficos, motivo da condenação, pena e reincidência criminal.

Foram utilizados, como fontes para tais anotações, os escritos primários retrospectivos, ou seja, os registros escritos no prontuário processual e de saúde das reeducandas.

Os achados coletados foram armazenados em um banco de dados, na planilha Excel. O programa Epi Info, versão 2000, foi utilizado para organizar os dados e apresentá-los de acordo com sua distribuição e frequência de aparecimento.

Foram adotadas, para este estudo, as seguintes variáveis: idade - em anos completos até o término do preenchimento dos protocolos; cor da pele - adotou-se a referência do Instituto Brasileiro de Geografia e Estatística (IBGE), que trabalha com a cor da pele conforme as seguintes categorias: branco, preto, pardo, amarelo e indígena; naturalidade -_distribuição por região do país, segundo o IBGE: Sudeste, Centro-Oeste, Sul, Nordeste e Norte; nupcialidade - abrange informações sobre a condição de convivência, estado civil e natureza da união, contemplando as categorias: solteira, casada/amasiada (união estável formal ou informal), separada/divorciada, viúva; número de filhos - variável expressa em números arábicos, sem considerar a variável gênero dos filhos; escolaridade - com base na Classificação Internacional Normalizada da Educação - CINE 1976, mais conhecida pela sua sigla em língua inglesa ISCED (International Standard Classification of Education) e considerando que, no Brasil, a educação se divide em educação básica (educação infantil com creche e pré-escola, ensino fundamental composto por 8 séries ou 9 anos e ensino médio de 3 anos, de acordo com a Lei ${ }^{\circ} 9394$, de 20 de dezembro de 1996, denominada Lei de Diretrizes e Bases da Educacão Nacional (LDB) e da Lei n ${ }^{\circ} 11.274$, de 6/2/2006, que estabelece a ampliação para nove anos do ensino fundamental) e ensino superior, optou-se por utilizar as variáveis: analfabeto, fundamental, médio e superior (esses 3 complementados por incompleto ou completo); religião - católica, evangélica (protestantes e pentecostais), espírita e outras (muçulmana, candomblé); ocupação - conforme Grandes Grupos Ocupacionais da Classificação Brasileira de Ocupações (CBO - Ministério do Trabalho e Emprego): Grupo 1 - Membros superiores do poder público, dirigentes de organizações de interesse público e de empresas e gerentes; Grupo 2 - Profissionais das ciências e das artes; Grupo 3 - Técnicos de nível médio; Grupo 4 - Trabalhadores de serviços administrativos; Grupo 5 - Trabalhadores dos serviços, vendedores do comércio em lojas e mercados; Grupo 6 - Trabalhadores agropecuários, florestais, da caça e pesca; Grupo 7 Trabalhadores da produção de bens e serviços industriais. Acrescentaram-se as variáveis: estudante e aposentado; motivo da condenação - crime pelo qual foram condenadas: drogas, crimes não violentos ou crimes violentos; duração da pena - em anos, e reincidência criminal - sim e não.

\section{Resultados}

Os resultados referentes às características sociodemográficas das reeducandas estudadas constam da Tabela 1 . 
Tabela 1 - Características sociodemográficas das reeducandas da Penitenciária Feminina de Ribeirão Preto, SP, Brasil, 2006

\begin{tabular}{|c|c|c|}
\hline Característica & $f$ & $\%$ \\
\hline \multicolumn{3}{|l|}{ Idade } \\
\hline $20 \vdash 30$ & 138 & 44,5 \\
\hline $30 \vdash 40$ & 99 & 32,0 \\
\hline $40 \vdash 50$ & 51 & 16,5 \\
\hline $50 \vdash 60$ & 20 & 6,4 \\
\hline $60 \vdash 72$ & 2 & 0,6 \\
\hline \multicolumn{3}{|l|}{ Cor da pele } \\
\hline Branca & 172 & 55,5 \\
\hline Parda & 100 & 32,3 \\
\hline Negra & 38 & 12,3 \\
\hline \multicolumn{3}{|l|}{ Naturalidade } \\
\hline Sudeste & 271 & 87,5 \\
\hline Nordeste & 15 & 4,8 \\
\hline Sul & 12 & 3,9 \\
\hline Centro-Oeste/DF & 9 & 2,8 \\
\hline Norte & 3 & 0,9 \\
\hline \multicolumn{3}{|l|}{ Nupcialidade } \\
\hline Solteira & 224 & 72,3 \\
\hline Casada/amasiada & 54 & 17,4 \\
\hline Separada/divorciada & 18 & 5,8 \\
\hline Viúva & 12 & 3,9 \\
\hline Sem registro & 2 & 0,6 \\
\hline \multicolumn{3}{|l|}{ Número de filhos } \\
\hline Nenhum & 42 & 13,5 \\
\hline 1 a 2 & 96 & 31,1 \\
\hline 3 a 6 & 64 & 20,6 \\
\hline Mais de 6 & 5 & 1,6 \\
\hline Sem registro & 103 & 33,2 \\
\hline \multicolumn{3}{|l|}{ Escolaridade } \\
\hline Analfabeto & 15 & 4,8 \\
\hline Fundamental incompleto & 185 & 59,7 \\
\hline Fundamental completo & 22 & 7,1 \\
\hline Médio incompleto & 43 & 13,9 \\
\hline Médio completo & 30 & 9,7 \\
\hline Superior incompleto & 10 & 3,2 \\
\hline Superior completo & 5 & 1,6 \\
\hline \multicolumn{3}{|l|}{ Religião } \\
\hline Católica & 180 & 58,1 \\
\hline Evangélica & 83 & 26,8 \\
\hline Espírita & 12 & 3,9 \\
\hline Outras & 3 & 0,9 \\
\hline Nenhuma & 17 & 5,5 \\
\hline Sem registro & 15 & 4,8 \\
\hline \multicolumn{3}{|l|}{ Ocupação* } \\
\hline Grupo 1 & 12 & 3,9 \\
\hline Grupo 2 & 7 & 2,3 \\
\hline Grupo 3 & 7 & 2,3 \\
\hline Grupo 4 & 21 & 6,7 \\
\hline Grupo 5 & 209 & 67,5 \\
\hline Grupo 6 & 1 & 0,3 \\
\hline Grupo 7 & 20 & 6,4 \\
\hline Estudante & 24 & 7,7 \\
\hline Aposentada & 3 & 1,0 \\
\hline Sem registro & 6 & 1,9 \\
\hline
\end{tabular}

Ocupação/Profissão: Grupo 1 - Membros superiores do poder público, dirigentes de organizações de interesse público e de empresas e gerentes; Grupo 2 - Profissionais das ciências e das artes; Grupo 3 - Técnicos de nível médio; Grupo 4 - Trabalhadores de serviços administrativos; Grupo 5 - Trabalhadores dos serviços, vendedores do comércio em lojas e mercados; Grupo 6 - Trabalhadores agropecuários, florestais, da caça e pesca; Grupo 7 - Trabalhadores da produção de bens e serviços industriais.
As 310 mulheres que constituíram a população deste estudo encontravam-se em faixa etária que variou de 20 a 72 anos de idade. A faixa compreendida entre 20 e 30 anos apresentou a maior frequência, com 138 (44,5\%) reeducandas.

Quanto à variável cor da pele, houve predomínio de 172 (55,5\%) da cor branca. A grande maioria (271-87,5\%) nasceu na Região Sudeste e, dessas, 251 (92,6\%) no Estado de São Paulo. A nupcialidade solteira foi frequente em $224(72,3 \%)$ das reeducandas. No que se refere aos dados de número de filhos, $103(33,2 \%)$ não tinham informações registradas nos documentos pesquisados; 165 $(53,3 \%)$ tinham pelo menos um filho; e 42 (13,5\%) não tinham filhos. Apenas $110(35,5 \%)$ tinham instrução igual ou superior ao fundamental completo e $200(64,5 \%)$ eram analfabetas ou não completaram o ensino fundamental. A maioria (180-58,1\%) pertencia à religião católica.

A variável ocupação/profissão teve as atividades do Grupo 5 como aquelas de maior frequência na população estudada (209-67,5\%). Desse grupo, 135 (43,5\%) dedicavam-se às atividades domésticas (ou afazeres da casa), remuneradas ou não. As demais (74-23,9\%) trabalhavam como balconistas (19-6,1\%), vendedoras ambulantes (10-3,2\%), promotoras de vendas (3-1,0\%), agente funerária $(1-0,3 \%)$, frentista $(1-0,3 \%)$, agente de saúde (1-0,3\%), lavadoras (9-2,8\%), cozinheiras (8-2,5\%), ajudantes de cozinha (3-1,0\%), garçonetes (3-1,0\%), manicures (7-2,3\%), cabeleireiras (4-1,2\%), babás (3-1,0\%), catadora de material reciclável (1$0,3 \%)$ e profissional do sexo $(1-0,3 \%)$. Das $21(6,7 \%)$ reeducandas do Grupo 4, $4(1,2 \%)$ eram secretárias, 4 $(1,2 \%)$ auxiliares de produção, $3(1,0 \%)$ ajudantes gerais, 2 $(0,6 \%)$ operadoras de telemarketing, $2(0,6 \%)$ operadoras de caixa e as $6(1,9 \%)$ restantes exerciam outras funções administrativas (recepcionista, auxiliar de escritório, bancária, encarregada de departamento de pessoal, digitadora e cobradora, respectivamente 1 de cada uma dessas ocupações). Exerciam atividades correspondentes ao Grupo 7, $20(6,4 \%)$ das participantes deste estudo, sendo $13(4,2 \%)$ costureiras, $2(0,6 \%)$ sapateiras, 3 $(1,0 \%)$ chapeiras em metalúrgicas, $1(0,3 \%)$ ourives e 1 $(0,3 \%)$ mototaxista, sendo que $12(3,9 \%)$ das mulheres pesquisadas eram comerciantes (Grupo 1). No referente às $7(2,3 \%)$ que se enquadravam no Grupo 3 da classificação de ocupações, $6(1,9 \%)$ eram auxiliares de enfermagem e $1(0,3 \%)$ professora. Do Grupo 2, do total de $7(2,3 \%)$, $4(1,2 \%)$ eram advogadas, $2(0,6 \%)$ artesãs e $1(0,3 \%)$ enfermeira. Apenas $1(0,3 \%)$ das reeducandas era boia-fria, pertencendo ao Grupo 6. $24(7,7 \%)$ eram estudantes sem especificação do nível de ensino. Das $3(1,0 \%)$ aposentadas não havia informação acerca da ocupação/profissão. Nos prontuários de $6(1,9 \%)$ não foram encontrados registros referentes à variável ocupação/profissão.

No que se refere à história penal, a distribuição das reeducandas, segundo o motivo da condenação (crime pelo qual foram condenadas) e reincidência ou não no crime, está revelada na Tabela 2. O motivo da condenação e a duração da pena em anos são apresentados na Tabela 3 . 
Tabela 2 - Distribuição das reeducandas de uma penitenciária feminina do interior paulista, segundo o motivo da condenação e reincidência. Ribeirão Preto, SP, Brasil, 2006

\begin{tabular}{|c|c|c|c|c|c|c|c|c|}
\hline \multirow{3}{*}{ Motivo da condenação } & \multirow{3}{*}{$f$} & \multirow{3}{*}{$\%$} & \multicolumn{6}{|c|}{ Reincidência } \\
\hline & & & \multicolumn{2}{|c|}{ Sim } & \multicolumn{2}{|c|}{ Não } & \multicolumn{2}{|c|}{ Sem registro } \\
\hline & & & $f$ & $\%$ & $f$ & $\%$ & $f$ & $\%$ \\
\hline $\begin{array}{l}\text { Drogas (uso, tráfico, formação de quadrilha, associação de pessoas) e combinado } \\
\text { com outro crime (fabricação, furto, roubo, uso de falsa identidade) }\end{array}$ & 196 & 63,3 & 36 & 11,6 & 148 & 47,7 & 12 & 3,9 \\
\hline $\begin{array}{l}\text { Crimes violentos (homicídios, lesão corporal, roubo, extorsão, sequestro e cárcere } \\
\text { privado, atentado violento ao pudor, roubo seguido de lesão corporal grave) }\end{array}$ & 74 & 23,9 & 15 & 4,8 & 56 & 18,1 & 3 & 1,0 \\
\hline $\begin{array}{l}\text { Crimes não violentos (furto, estelionato, falsa identidade, facilitação de fuga de } \\
\text { preso, formação de quadrilha, motim de presos, receptação de produtos ilegais) }\end{array}$ & 25 & 8,0 & 13 & 4,2 & 10 & 3,2 & 2 & 0,6 \\
\hline Sem registro & 15 & 4,8 & 1 & 0,3 & 10 & 3,2 & 4 & 1,2 \\
\hline Total & 310 & 100 & 65 & 21,0 & 224 & 72,2 & 21 & 6,8 \\
\hline
\end{tabular}

O envolvimento com drogas (tráfico e uso) combinado ou não com outro crime constituiu o delito de maior ocorrência com frequência de 196 (63,3\%). Nos prontuários de $15(4,8 \%)$ não foram encontrados registros referentes à variável motivo da condenação, sendo que, dessas, $1(0,3 \%)$ era reincidente e $10(3,2 \%)$ não, e para as $4(1,2 \%)$ restantes não havia dado disponível acerca dessa variável.

No referente à reincidência criminal, $224(72,2 \%)$ eram primárias, ou seja, não reincidentes, e 65 (21,0\%) eram reincidentes. Os prontuários das demais (21-6,8\%) não continham informações sobre a reincidência criminal das mesmas.

Tabela 3 - Distribuição das reeducandas de uma penitenciária feminina do interior paulista, segundo o motivo da condenação e a duração da pena em anos. Ribeirão Preto, SP, Brasil, 2006

\begin{tabular}{|c|c|c|c|c|c|c|}
\hline \multirow{3}{*}{$\begin{array}{l}\text { Duração da } \\
\text { pena (anos) }\end{array}$} & \multicolumn{6}{|c|}{ Motivo da condenação } \\
\hline & \multicolumn{2}{|c|}{ Drogas } & \multicolumn{2}{|c|}{$\begin{array}{c}\text { Crimes não } \\
\text { violentos }\end{array}$} & \multicolumn{2}{|c|}{$\begin{array}{c}\text { Crimes } \\
\text { violentos }\end{array}$} \\
\hline & $f$ & $\%$ & f & $\%$ & f & $\%$ \\
\hline $1 \vdash 4$ & 108 & 34,8 & 12 & 3,9 & 3 & 0,9 \\
\hline $5 \vdash 8$ & 42 & 13,5 & 3 & 0,9 & 23 & 7,4 \\
\hline $9 \vdash 12$ & 5 & 1,6 & 2 & 0,6 & 7 & 2,2 \\
\hline $13 \vdash 16$ & 4 & 1,3 & 0 & 0,0 & 7 & 2,2 \\
\hline $17 \vdash 20$ & 2 & 0,6 & 0 & 0,0 & 7 & 2,2 \\
\hline $21 \vdash 24$ & 0 & 0,0 & 0 & 0,0 & 5 & 1,6 \\
\hline $24 \vdash 47$ & 0 & 0,0 & 0 & 0,0 & 6 & 1,9 \\
\hline Indefinida & 33 & 10,6 & 8 & 2,6 & 15 & 4,8 \\
\hline $\begin{array}{l}\text { Sem registro } \\
\text { da pena }\end{array}$ & 2 & 0,6 & 0 & 0,0 & 1 & 0,3 \\
\hline Total & 196 & 63,0 & 25 & 8,0 & 74 & 23,5 \\
\hline
\end{tabular}

Neste estudo, do total de 310 presas, $205(66,1 \%)$ cumpriam pena de 1 a 12 anos de reclusão e 31 (10,0\%) acima de 13 anos. Para 59 (19,0\%) das reeducandas não se encontrou anotação sobre a duração da pena (56 indefinidas e 3 sem registro). Não havia registro sobre o motivo da condenação em $15(4,8 \%)$ dos prontuários consultados.

Entre as mulheres presas por delitos relacionados a drogas (uso, tráfico e combinados com outros crimes),
$155(79,1 \%)$ tinham pena de até 12 anos, $4(2,0 \%)$ de 13 a 16 anos, e $2(1,0 \%)$ com 17 a 20 anos, respectivamente. Em relação aos crimes qualificados como não violentos, $17(68,0 \%)$ foram condenadas a penas de 1 a 12 anos. Das detentas, cujos crimes foram especificados como violentos, $33(44,5 \%)$ tiveram pena imposta de até 12 anos de reclusão e 25 detentas $(33,7 \%)$ tiveram pena maior que essa. A maior penalidade foi de 47 anos, atribuída a uma mulher por crime violento (homicídio).

\section{Discussão}

A população carcerária feminina brasileira, em 2006, segundo dados do Relatório sobre mulheres encarceradas no Brasil ${ }^{(5)}$, era de 15.833 mulheres, sendo 7.023 (44,4\%) dessas concentradas na Região Sudeste e 4.359 (27,5\% do país e $62,1 \%$ da região) no Estado de São Paulo. A Região Sudeste é a que apresenta o maior número de mulheres presas em todo o Brasil. Na Penitenciária Feminina de Ribeirão Preto, no período estudado, a população era composta predominantemente por jovens na faixa de 20 a 30 anos, com mediana de 31 anos, resultado equivalente ao encontrado na literatura nacional ${ }^{(3,5,7-10)}$.

Nos registros consultados, a cor branca da pele foi a que predominou em $172(55,5 \%)$ das reducandas. A classificação adotada para nomear as raças ou etnias que compõem a população brasileira, de acordo com o IBGE, estabelece que o termo "população negra" abrange as pessoas de cor preta e parda, em conjunto. Neste estudo, portanto, $138(44,6 \%)$ das mulheres pertenciam à população negra. Esses achados diferem dos encontrados em outras pesquisas realizadas na Região Sudeste, como, por exemplo, no Rio de Janeiro, onde, do total de $524^{(3)}$ mulheres encarceradas, 56,4\% eram negras, e no Espírito Santo, em que, de 122 presidiárias, 57,8\% eram negras e $42,1 \%$ brancas $^{(4)}$. Essas diferenças talvez sejam explicadas pelas diversidades regionais, observadas na composição étnica de cada uma dessas populações.

Os achados de estudo realizado no Paraná(11) corroboram a hipótese de diferenças regionais na disposição étnica populacional brasileira. Nesse Estado, de 332 detentas estudadas $72 \%$ eram brancas, $25,1 \%$ eram pardas e as demais 2,9\% se distribuíam entre negras e amarelas. A conclusão dessa pesquisa apontou como 
justificativa a forte imigração estrangeira na composição da população do Estado como um todo, em detrimento da possível ausência de preconceito racial. Além disso, já foi constatado que os moradores das favelas paranaenses não são apenas negros, mas migrantes brancos e pobres provenientes de áreas agrícolas, das quais são expulsos.

Justificativas semelhantes podem explicar os resultados do presente estudo. Após a abolição da escravidão no Brasil, houve estímulo ao afluxo de imigrantes europeus (especialmente italianos) para a região de Ribeirão Preto. Por sua vez, essa região é caracterizada pelo agronegócio, com ênfase nas lavouras e usinas de cana-de-açúcar, o que atrai fluxo de migração de outras regiões do país, em especial do Nordeste. A cidade de Ribeirão Preto caracteriza-se como polo de atração de atividades comerciais e de prestação de serviços da região.

Em artigo sobre a Penitenciária Feminina de Salvador ${ }^{(12)}$, do grupo de 124 presidiárias estudadas, $92,7 \%$ eram solteiras, $6,5 \%$ casadas e $0,8 \%$ separadas ou divorciadas. No Rio de Janeiro ${ }^{(9)}, 54,4 \%$ das 125 detentas eram solteiras, $21,6 \%$ casadas ou amasiadas, $14,4 \%$ separadas ou divorciadas e 9,6\% viúvas. Em Curitiba ${ }^{(11)}$, de 332 presas, 52,5\% eram solteiras, $32,5 \%$ casadas ou amasiadas, $10,5 \%$ separadas ou divorciadas e $4,7 \%$ viúvas. Por outro lado, dados de uma penitenciária feminina do Espírito Santo ${ }^{(4)}$ mostraram equilíbrio numérico entre as mulheres solteiras e as que tinham algum tipo de união. Das 121 participantes do referido estudo, 38,8\% eram casadas ou amasiadas, 37,2\% solteiras, 13,3\% separadas ou divorciadas e $10,7 \%$ viúvas. Os sujeitos deste estudo apresentaram distribuição semelhante à do estudo realizado na cidade do Rio de Janeiro. Nessa cidade, a distribuição se deu da seguinte forma: 224 (72,3\%) mulheres solteiras, estando $194(62,6 \%)$ na faixa etária dos 20 aos 39 anos e $30(9,7 \%)$ dos 40 aos 72 anos. $54(17,4 \%)$ casadas ou amasiadas, $36(11,6 \%)$ na faixa dos 20 aos 39 anos de idade e $18(5,8 \%)$ entre 40 e 72 anos de idade. Separadas ou divorciadas somaram $18(5,8 \%)$ reeducandas, sendo 6 $(1,9 \%)$ com idade entre 20 e 39 anos e $12(3,9 \%)$ entre 40 e 72 anos. As viúvas totalizaram $12(3,9 \%)$, sendo $1(0,3 \%)$ com idade de 31 anos e $11(3,6 \%)$ entre 40 e 72 anos de idade.

Ao se analisar a variável número de filhos, constatouse que $165(53,3 \%)$ reeducandas tinham pelo menos um filho. Dessas, 52 (31,5\%) eram casadas, amasiadas, viúvas ou divorciadas/separadas, estando $25(15,1 \%)$ na faixa etária de 20 a 39 anos e $27(16,4 \%)$ na de 40 a 72 anos. As demais, 113 (68,5\%), eram solteiras, 93 (56,4\%) com idade compreendida entre 20 e 39 anos e $20(12,1 \%)$ entre 40 e 72 anos. No Rio de Janeiro, de acordo com o Relatório sobre mulheres encarceradas no Brasil ${ }^{(5)}, 84 \%$ das presas tinham filhos. Não se encontrou referência a dados acerca dessa variável, em estudos realizados em outros Estados, para se estabelecer comparações.

A afiliação à Igreja Católica foi expressiva neste estudo: $180(58,1 \%)$ das reeducandas declaram pertencer a essa religião. Esse dado está de acordo com os de pesquisa realizada em penitenciaria feminina no Rio de Janeiro, na qual 41,2\% das mulheres se declararam católicas, sendo esse percentual o dobro em relação às evangélicas ${ }^{(3)}$. Em estudo realizado na cidade de São Paulo ${ }^{(10)}, 94$ (26\%) eram católicas e 151 (42,0\%) evangélicas, antes da prisão. Nos dados colhidos durante o tempo de aprisionamento, 201 (56,2\%) declararam ser afiliadas a igrejas evangélicas, número considerado pelos autores surpreendentemente alto. As conversões em direção às religiões evangélicas, de acordo com os pesquisadores, podem ser explicadas pela crescente e permanente atuação de grupos de evangelização, sobretudo as pentecostais, dentro e fora dos sistemas prisionais $^{(3,10)}$.

$\mathrm{Na}$ última década, houve melhoria na situação educacional do país. No ano 2000, as mulheres alcançaram o mesmo patamar de alfabetização, com ligeira vantagem, quando esse patamar é comparado à situação dos homens alfabetizados ${ }^{(13)}$. Apesar dessa sensível melhoria das condições educacionais da população feminina, assegurada pelo artigo 18 da Lei de Execução Penal ${ }^{(14)}$, na situação de carceragem há vários estudos que confirmam índice maior de baixos níveis de escolaridade ${ }^{(3-4,9)}$. De acordo com o Relatório sobre mulheres encarceradas no Brasil $^{(5)}, 65 \%$ ou são analfabetas ou não possuem o ensino fundamental completo. Essa realidade foi confirmada nos achados da presente pesquisa, em que 200 detentas $(64,5 \%)$ não frequentaram a escola ou não completaram o ensino fundamental. Não se pode, no entanto, inferir, neste estudo, que a baixa escolaridade esteja relacionada à entrada no sistema penal. Há outros motivos que a justificariam como: casamento precoce, situação de rua, falta de incentivo, uso de drogas, envolvimento no crime, problemas de saúde, distância da escola e expulsão da mesma $^{(3)}$.

Estudos com a população brasileira revelam que a segmentação ocupacional no Brasil é uma das mais evidentes, em especial no que se refere ao trabalho feminino ${ }^{(15)}$. É observado que essa se concentra em poucas atividades no setor de prestação de serviços, como serviços pessoais, administração pública, saúde, ensino, serviço comunitário e comunicações. As mulheres que se dedicam à área de prestação de serviços representam 29,4\%, enquanto $13,7 \%$ são encontradas envolvidas em atividades agrícolas, 17,4\% em prestação de serviços sociais, 17,0\% em emprego doméstico, 13,5\% no comércio e 9,0\% na indústria ${ }^{(15)}$. Neste estudo, houve predomínio (67,5\%) de mulheres que exerciam atividades do Grupo 5 da CBO, sendo que $43,5 \%$ se dedicavam às tarefas domésticas remuneradas ou não. Uma das explicações para esse achado pode ser a baixa escolaridade das reeducandas (64,5\% não frequentaram a escola ou não completaram o ensino fundamental), pois isso pode ter influenciado diretamente no tipo de ocupação dessas mulheres. A baixa escolaridade pode corroborar o abuso de álcool e outras drogas, preconceito racial e com os problemas macrossociais como desemprego e pobreza, relacionados à participação ou prática de crimes $^{(9,15-16)}$.

Nos últimos anos, houve considerável aumento no número de mulheres encarceradas por envolvimento no tráfico de drogas, tanto por traficarem como por usarem. Esse tipo de crime correspondia a 32,6\% das detenções 
de mulheres em 1988, passando para 56,1\% em $2000^{(8)}$. O envolvimento com drogas (tráfico e uso), combinado ou não com outro crime, constituiu o delito de maior ocorrência entre as reeducandas, com frequência de 196 (63,3\%). A maioria dessas (155-79,1\%) cumpria pena de até 12 anos de reclusão. Na literatura, há dados que indicam diferença entre homens e mulheres quanto à criminalidade ${ }^{(17)}$. As mulheres participam em menor número que os homens nos delitos e em posição subalterna, de menor importância. Consideradas mais emotivas e influenciadas por estados fisiológicos, tendem a ser qualificadas como perigosas, não confiáveis e capazes de traição.

No referente à reincidência criminal, das 310 mulheres encarceradas pesquisdas neste estudo, 65 (21,0\%) eram reincidentes e $224(72,2 \%)$ primárias. Dados do Relatório sobre mulheres encarceradas no Brasil ${ }^{(5)}$ mostraram que $72 \%$ dessas eram primárias. Estudo com presas no Rio de Janeiro $^{(9)}$ mostrou que, do total de 125 , apenas $16(12,9 \%)$ eram reincidentes. No Relatório do Departamento Jurídico da Penitenciária Feminina do Paraná de $2005^{(11)}$ consta que, do total de 332 detentas, 34 (10,2\%) eram reincidentes. Já em estudo na Bahia ${ }^{(12)}, 30 \%$ das presas eram reincidentes. Os dados da literatura em relação à reincidência criminal mostram-se, portanto, semelhantes aos achados deste estudo. Pesquisadores têm tentado sugerir possíveis causas para justificar a reincidência criminal na população feminina. A falta de oportunidades das egressas do sistema para conseguirem emprego contribui para que voltem à prisão ${ }^{(12,18)}$. A discriminação social devido à manutenção do estigma de ex-presidiária pode, também, contribuir para a reincidência no crime ${ }^{(12,18-19)}$.

A criminalidade pode ser relacionada a dois fatores, um de ordem pessoal e outro ambiental ${ }^{(20)}$. O primeiro é decorrente de características inerentes ao indivíduo, constitucionais ou introjetadas. O segundo é influenciado pelo meio sociocultural em que o indivíduo se encontra e a atuação do ecossistema sobre ele. O ser humano é sujeito ao sentimento de frustração e reage a esse sentimento com atitudes e intensidades diferentes, de acordo com suas características pessoais $^{(21)}$. A frustração é reconhecida como a principal causa da eclosão da violência. Provém e é fomentada pela competitividade da sociedade, pela dificuldade em acessar as fontes de gratificação, pelo aumento constante do custo de vida, com o aumento da incerteza e do medo do desemprego consequentes, fatores aliados à impossibilidade de planejar o futuro. Essas diferenças agravam a inveja e a rivalidade no mundo dividido entre pobres e ricos, realimentando essa frustração que, novamente, conduz à violência e à criminalidade ${ }^{(20-21)}$.

\section{Considerações Finais}

Neste estudo, foi possível conhecer o perfil e a história penal das reeducandas da Penitenciária Feminina de Ribeirão Preto. Trata-se de população em sua maioria constituída por mulheres jovens, brancas, naturais do Estado de São Paulo, solteiras, com pelo menos um filho, católicas, baixa escolaridade e ocupações relacionadas a atividades domésticas. O envolvimento com drogas (tráfico e uso), combinado ou não com outro crime, foi o delito mais observado. A maior parte cumpria pena de 1 a 12 anos de reclusão e estava aprisionada pela primeira vez.

Acredita-se que, a partir da apresentação dos achados deste estudo, será possível desenvolver pesquisas que tenham como objetivo identificar o conhecimento das reeducandas sobre o tema violência (tipos e natureza), esclarecer as condições ou situações de vida às quais essas mulheres foram expostas e que possam ter contribuído com seu encarceramento, caracterizar a vida no cárcere e conhecer os resultados dos programas de reabilitação existentes.

É sabido que em estudos que usam documentos como fonte de pesquisa pode haver perdas, como consequência da falta de registro de informações. Neste estudo, percebeuse que as anotações consultadas, além de incompletas, podem ser melhoradas, especialmente no que se refere ao prontuário de saúde. Sugere-se, dessa forma, a inclusão de informações que podem ser importantes como a precocidade ou não do casamento, a qualidade da moradia, o incentivo e a motivação para estudar e buscar formação profissional, o comportamento e o desempenho escolar, o uso de drogas, a renda familiar, a história de vitimização e a participação anterior em atos violentos.

Outro acréscimo que poderia ser interessante seria a criação de um espaço nos relatórios, para manifestações livres dessas mulheres, acerca de suas percepções quanto à própria situação de cárcere e das circunstâncias que motivaram essa reclusão. Para tanto, é preciso que os profissionais, por sua vez, percebam a importância de registros bem feitos e que sejam incentivados a fazê-lo.

\section{Referências}

1. Código Penal Brasileiro. Lei Federal N. 2.848 de 7 de dezembro de 1940, alterado pela Lei n 7209 de 11 de julho de 1984.

2. Foulcault M. Vigiar e punir: nascimento da prisão. $4^{\mathrm{a}} \mathrm{ed}$. Rio de Janeiro(RJ): Vozes; 1986.

3. Soares BM. Retrato das mulheres presas no estado do Rio de Janeiro. Bol Segurança e Cidadania 2002;1(1):1-8. 4. Miranda AP, Vargas PRM, Viana MC. Saúde sexual e reprodutiva em penitenciária feminina, Espírito Santo, Brasil. Rev Saúde Pública 2004;38(2):255-60.

5. Relatório sobre mulheres encarceradas no Brasil. Documento apresentado à Corte Interamericana de Direitos Humanos com o apoio do Comitê Latino- Americano e do Caribe para a Defesa dos Direitos da Mulher CLADEM e Programa para a América Latina da International Women's Health Coalition. fev 2007. [acesso 13 out 2009]. Disponível em: http://www.cladem.org/portugues/ nacionais/brasil/brasil.asp.

6. Lakatos EM, Marconi MA. Fundamentos de metodologia científica. $4^{\mathrm{a}}$ ed. São Paulo (SP): Atlas; 2001.

7. Strazza L, Carvalho H, Azevedo RS, Massad E. Estudo da vulnerabilidade à infecção DST/AIDS em detentas de uma penitenciária Feminina de São Paulo-SP, Brasil, avaliada Pela técnica sorológica DST. J Bras Doenças Sex Transm. 2003;15(4):27-32. 
8. Departamento de derecho político (UNED) [homepage na Internet] Madrid: Departamento de derecho político (UNED); maio 2005 [acesso 10 ago 2009]. Observatorio Penitenciario: Foro de debate. Políticas penitenciarias en derecho comparado. Integridade física da mulher que cumpre pena em estabelecimento penal no Brasil; [5 telas]. Disponível em: http://www.uned.es/dpto-derecho-politico/ foroVVAA2.pdf.

9. Carvalho ML, Valente JG, Assis SG, Vasconcelos AGG. Perfil dos internos no sistema prisional do Rio de Janeiro: especificidades de gênero no processo de exclusão social. Ciênc Saúde Coletiva. 2006;11(2):461-71.

10. Moraes PAC, Dalgalarrondo P. Mulheres encarceradas em São Paulo: saúde mental e religiosidade. J Bras Psiquiatr. 2006;55(1):50-6.

11. Quintino AS. Creche na prisão feminina do Paraná: humanização da pena ou intensificação do controle social do estado? [Dissertação]. Paraná (PR): Universidade Federal do Paraná; 2005.

12. Cavalcanti VRS. Vivendo atrás das grades: mulheres, direitos humanos e políticas públicas. Bahia Análise \& Dados. 2004;14(1):185-96.

13. Instituto Brasileiro de Geografia e Estatística (IBGE). Estudos e Pesquisas Informação Demográfica e Socioeconômica número 8. Perfil das mulheres responsáveis pelos domicílios no Brasil 2000. Rio de Janeiro (RJ); 2002.

14. Lei Federal N. 7210 de 11 de julho de 1984 (BR). Institui a Lei de Execução Penal. Diário Oficial da União (Brasília). 13 jul 1984.

15. Yannoulas SC Dossiê: Políticas públicas e relações de gênero no mercado de trabalho. Brasília (DF): CFEMEA; 2002.

16. Marín-León L, Oliveira HB, Barros MBA, Dalgalarrondo P, Botega NJ. Percepção dos problemas da comunidade: influência de fatores sócio-demográficos e de saúde mental. Cad Saúde Pública. 2007;23(5):1089-97. 17. Guedes MA. Intervenções psicossociais no sistema carcerário feminino. Psicol Ciênc Profissão. 2006; 26(4):558-69.

18. Bordin N, Bordin ICB. O perfil do egresso prisional. Ciênc Soc Perspectiva. 2007;6(11):27-38.

19. Carlen P. A reclusão de mulheres e a indústria de reintegração. Anál Soc. 2007;42(185):1005-19.

20. Cohen C, Ferraz FC, Segre M, organizadores. Saúde mental, crime e justiça. São Paulo (SP): EDUSP; 1996.

21. Pichon-Rivière E, Quiroga AP. Psicologia da vida cotidiana. São Paulo (SP): Martins Fontes; 1998.

\section{Como citar este artigo:}

Scherer ZAP, Scherer EA, Nascimento AD, Ragozo FD. Perfil sociodemográfico e história penal da população encarcerada de uma penitenciária feminina do interior do estado de São Paulo. SMAD, Rev. Eletrônica Saúde Mental Álcool Drog. (Ed. port.). maio-ago. 2011 [acesso: ];7(2):PAGINAÇÃO DO ARTIGO. Disponível em:

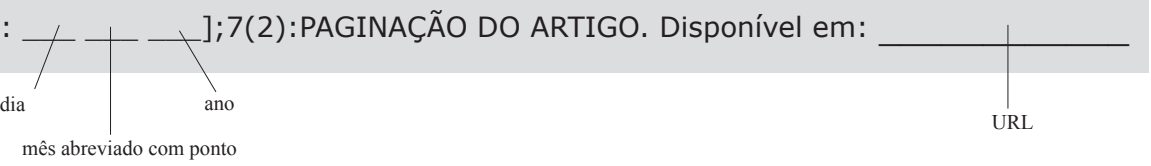

